\title{
MODIS DERIVED NDVI BASED TIME SERIES ANALYSIS OF VEGETATION IN THE JODHPUR AREA
}

\author{
S.K.Yadav ${ }^{1 *}$, S.L. Borana ${ }^{1}$ \\ ${ }^{1}$ Remote Sensing Group, Defence Laboratory, Jodhpur-342011- (*skyadavgeo, sohanlb)@ gmail.com
}

KEY WORDS: Arid Region, NDVI, MODIS, Vegetation Change

\begin{abstract}
:
Arid region of India shows vast variation in climate and vegetation during last two decades. In order to analysis impact of monsoonal patterns on the vegetation indices of the arid zone, a three years (2015-2017) temporal series Moderate Resolution Image Spectrometer (MODIS) data for Pre \& Post Monsoon was used for computing Normalized Difference Vegetation Index (NDVI). The cloud-free NDVI time series data are used to study the relationship between the rainfall pattern and the vegetation changes in Jodhpur District. ENVI and ArcGIS image processing software are used to evaluate and monitor the vegetation for the pre-monsoon and postmonsoon seasons for three years. Enormous changes were observed during pre and post monsoon temporal analysis. This study shows that MODIS NDVI data is best suited for quick vegetation assessment in arid region.
\end{abstract}

\subsection{INTRODUCTION}

Vegetation available in arid zone is useful for livelihood of people and cattle stock. Due to changing in conditions, mapping of arid vegetation become a great challenge for civic authorities of the region. Arid part of the western India covers large area with varieties of natural resources. Due to large area of arid region and scarcity of water, its mapping and monitoring become challenging task for the researchers. Many studies have tried to understand vegetation condition from satellite images, to distinguish anthropogenic land degradation or desertification by comparing the potential and actual status of vegetation (Hanafi and Jauffret, 2008; Holm et al.,2003). It has been reported that around 30 per cent of the total land area of the country is undergoing degradation (SAC, 2016). Detailed reporting at a regional scale over India is required especially in areas around dry lands, but lack of up-to-date spatial data at a regional scale is a major drawback. Important indicators of land degradation and desertification for example in the form of soil maps, geological maps, or spatial data on land cover, land use, and livestock distribution were either not available or obtained at a very coarse resolution. Avoiding all these constrains,land degradation and regeneration monitoring was done over western Rajasthan region of India with Moderate Resolution Imaging Study Area Spectroradiometer (MODIS) satellite data of two decades using time series trend analysis. It was hypothesized that the derived Normalised Differential Vegetation Index (NDVI) trend vectors might successfully detect changes in photosynthetically active vegetation and serve as an indicator for land degradation and regeneration processes.

Arid areas in India, which falls within the rainfall zones, $100-$ $500 \mathrm{~mm}$, under a dominant sandy terrain, experience gradual change in natural vegetation in various habitats. Thus, these regions are more vulnerable to land degradation. Adequate Information through various studies are available now to specify the major causes for land degradation in this region using both field based interpretation and remote sensing. Sikka, D.R, 1997 studied the land degradation correlated with the climate change. Kar, et al 2009, based on the national level mapping evaluate various types of the land degradation in India and presented a national level desertification database. Kaushalya R. et al, 2013, evaluate vulnerability of the Indian agriculture to rainfall changeability using NOAA-AVHRR and MODIS with $250 \mathrm{~m}$ data. PiaoShilong et al. 2005 utilize NDVI toindicate desertification decline in China in past two decades. Santra and Chakrtaborty, 2011, analyzed both seasonal and annual change in vegetation and found suitability of MODIS data for quick assessment of vegetation changes in TharDesert.The present study is undertake to study the vegetaion availability of Jodhpur district of the arid part during three years with two season using available MODIS data.

\subsection{Normalized Difference Vegetation Index (NDVI)}

NDVI index allowing to generate an image displaying greenness. It takes advantage of the contrast of the two bands from a multispectral raster dataset, the pigment chlorophyll absorptions in red band and the high reflectivity of the plant materials in the near-infrared (NIR) band. NDVI is often used to monitor drought, predict agricultural production, assist in hazardous fire zones predicting, and map desert encroachment. The NDVI is selected for global monitoring of vegetation because it helps to balance for changing illumination conditions, aspect, surface slope and other extraneous factors (Lillesand 2004). The NDVI equation is as follows:

$\mathrm{NDVI}=((\mathrm{IR}-\mathrm{R}) /(\mathrm{IR}+\mathrm{R}))$

- $\quad \mathrm{IR}=$ pixel values from the infrared band

- $\mathrm{R}=$ pixel values from the red band

The index outputs values range between -1.0 and 1.0 , generally representing greenness, where negative values are mostly generated from clouds, snow, water, and values near zero are generally generated from rock and bare soil. The barren areas of rock has very low values ( 0.1 and below) of NDVI correspond to, snow or sand. Shrub and grassland have moderate values ( 0.2 to 0.3$)$ and high values ( 0.6 to 0.8$)$ indicate tropical rainforests and temperate.

\subsection{Enhanced Vegetation Index (EVI)}

Where NDVI is sensitive for RED variations, and thus responsive to chlorophyll, is EVI is more sensitive to NIR, and so, more responsive to canopy structural variations, including the leaf area index (LAI), canopy type and architecture EVI $=2.5(\rho$ NIR - pred $) /(\rho$ NIR $+6 \rho$ red $-7.5 \rho$ blue +1$)$

It is because of the blue band, who corrects the red band for atmospheric influences, that many of the atmospheric contaminations NDVI has to deal with, such as residual aerosol influences, are minimized (Huete et al., 2002; Pettorelli et al., 2005).

\subsection{STUDY AREA}

Jodhpur district is among the largest districts in the state of Rajasthan. It is centrally situated in the western part of the state and covers a total geographical area of $22850 \mathrm{Sq} \mathrm{Km}$. The 
Jodhpur district is located at $26^{\circ} \mathrm{N} 0^{\prime}$ and $27^{\circ} 37^{\prime}$ north latitude and $72^{\circ} 55^{\prime}$ and $73^{\circ} 52^{\prime}$ east longitude. It is bounded by Nagaur in the east, Jaisalmer in the west, Bikaner in the north and Barmer and Pali in the South. The total length of the district from north to south is about $197 \mathrm{~km}$ and from east to west it is about $208 \mathrm{Km}$ with an average altitude of $224 \mathrm{~m}$ above mean sea level (Fig.1). Topographically the district comes under arid zone of the state and covers 11.60 percent of the total area of the arid zone of the state. The general slope of the terrain is towards west. There is no perennial river in the district, but important rivers viz. Lunu and Mithari become active during rainy season. Main source of irrigation besides rainwater are dug-well and tube wells. The highest irrigated area in the district is in Bilara Tehsil followed by Bhopalgarh and Osian Tehsil. The Soil of the district is classified mainly as sandy and loamy. Bajra is the major crop in the kharif season. In Rabi, wheat, pulses and variety of spices like Cumin, Coriander and red chili are also grown. The major and important minerals of the area are sandstone and limestone. Minerals like quartz and clays of various colours and dolomite are also available in the district.

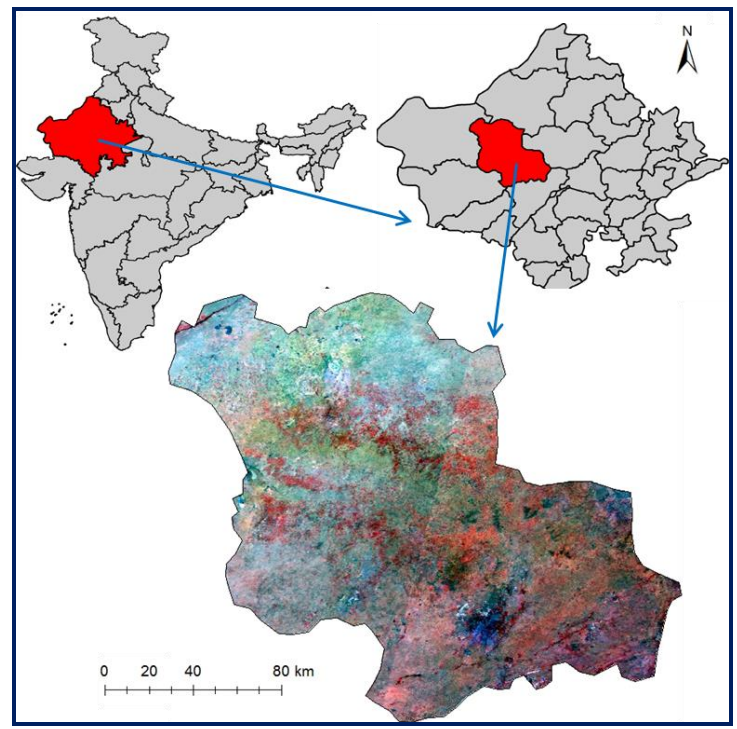

Fig.1. Location map of study area

\subsection{Soil and Agricultural Crops}

Soil of Rajasthan has got significant role in the economy of the state. The Soil type is classified mainly as sandy and loamy. Agriculture becomes very difficult as a major portion of the state is parched and infertile.Northwestern Rajasthan is irrigated by the Indira Gandhi Canal. Rajasthan has two principal crop seasons - Rabi \&Kharif.The Rabi crops are winter crops and are sown in the months of October and November and are harvested in the months of March and April. The principal Rabi crops are Barley, Wheat, Gram, Pulses and Oil Seeds. The major oil seeds are Rape and Mustard.

The Kharif crops are the crops that are grown in the summer season and are seeded in the months of June and July. These crops are harvested in the months of September and October and include Bajra, Pulses, Jawar, Maize and Ground Nuts. Bajara (pearl millet) is the major crop in kharif. Jodhpur has excellent ground water taste in many part of district. In rabi wheat, pulse and a variety of masala like jeera, Dhania and red chilly are also grown. Jodhpur has a name for its red chilly, onion and garlic. It is one of the major production centres for guar.

\subsection{Climatic conditions}

Rainfall (Precipitation): The rainfall in the area is erratic and there are frequent draughts. The bulk of the rainfall $(82.3$ per cent) in a year occurs in three months from July to September (Fig. 2).

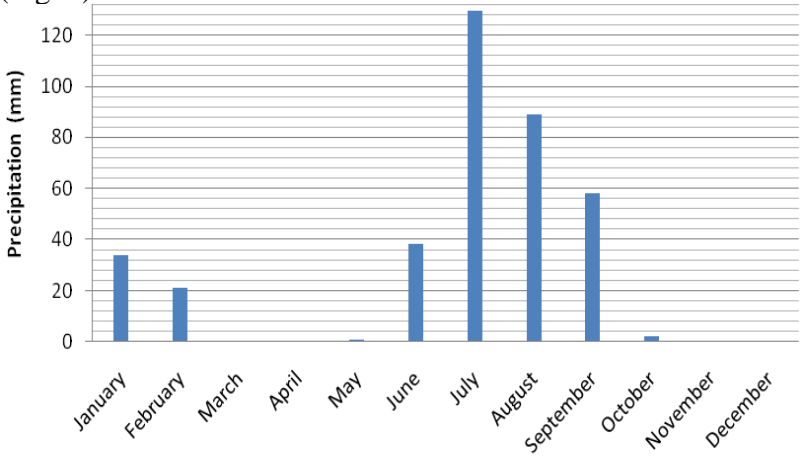

Fig. 2. Monthly Rainfall (mm) in Jodhpur (Source: IMD, Delhi).

\subsection{DATA USED AND METHODOLOGY}

\subsection{Satellite data}

The Moderate Resolution Imaging Spectroradiometer (MODIS) datasets are recorded by NASA's Terra platform on board two sun-synchronous satellites, near-polar orbit at $705 \mathrm{~km}$ altitude and cross the equator every day at 10:30 am local time. The MODIS instrument includes seven spectral bands that are explicitly designed for land surface monitoring (Justice et al., 1997). In this study, MOD13Q1 is the 16-day $250 \mathrm{~m}$ vegetation index product that gathers information on a per-pixel basis through multiple observations over a sixteen day period. Two pre-monsoon (julian day 145 and 129) and two post-monsoon (julian day 289 and 305) NDVI products with a spatial resolution of $250 \mathrm{~m}$ during each of the year 2015, 2016 and 2017 were downloaded from Land Processes Distributed Active Achieve Centre (LPDAAC) (ftp://e4ft101.cr.usgs.gov/MOLT/ MOD13Q1.005). By using the MODIS Reprojection Tool (version 4.0), all the downloaded images were processed, reprojected, and saved in GeoTiff format (Fig.3). IRS - AWiFs data were used as secondary data for checking vegetated area. The data has been downloaded for the years 2015 - 2017. Pre and Post Monsoon period (May and Oct) were selected for observation.

\subsection{Processing of MODIS data using ArcGIS}

The conversion of NDVI data of MODIS from 16 bit integer to 32 bit float to get the original values $(+1$ to -1$)$ since this data did not contain cloud covers and atmospheric disturbances, therefore, the procedures to remove such errors were not followed. The Satellite imagery in respect of the study area was extracted. Generation of yearly Average scenes by raster calculator for each year. Visual observation of value range from the year 2015 to 2017. Then obtained max and min range of NDVI values $(0-0.65)$. On the basis of this range, we have classified all the scenes into three categories $(0.78 / 3)$ as $0-0.24$ (low), 0.25-0.39 (Moderate) and 0.40-0.78 (High) using ArcGIS spatial analysis tool. Statistics generation and area calculation 
for each class. Analysis of rainfall pattern of the study area from 2015 to 2017.

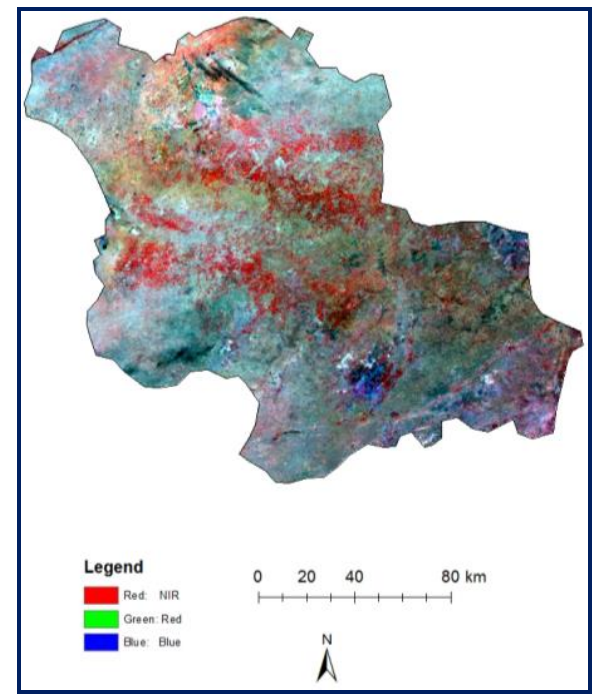

Fig.3. FCC MODIS Image of Study Area

\subsection{Rainfall of the Jodhpur District:}

Annual rainfall pattern of Jodhpur district is presented in Fig. 2. During 2015, 2016, and 2017 for which NDVI products are analysed in this study, total annual rainfall was 130.7, 385.7, $70.4 \mathrm{~mm}$ at Jodhpur. Year 2015 was considered as normal rainfall, whereas year 2016 and 2017 were considered as surplus and deficit year, respectively. Rainfall data over the years (2015 to 2017) for Jodhpur district plotted to understand the rainfall variability and pattern (Fig.4).

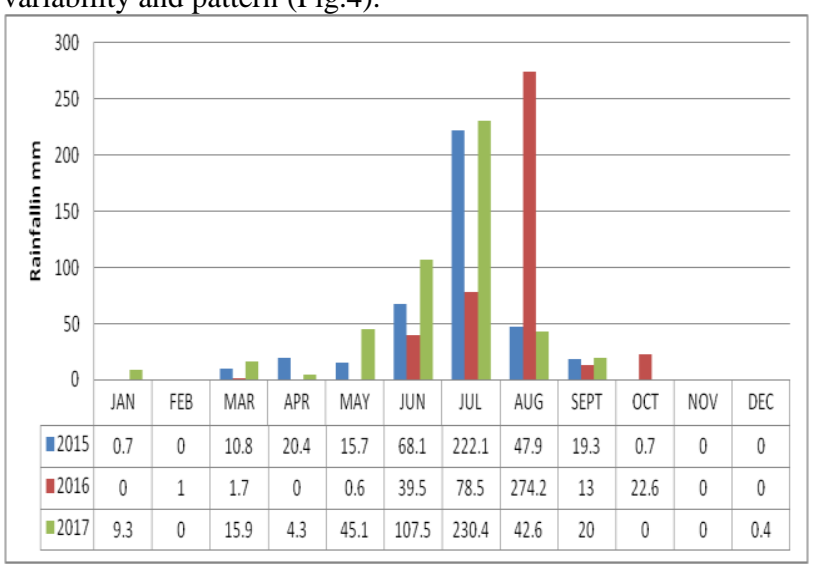

Fig. 4. Rainfall variability in Jodhpur district from 2015 to 2017 (Source: IMD, Delhi).

\subsection{RESULTS \& DISCUSSION}

\subsection{Temporal and spatial variation in NDVI}

Classified NDVI and EVI maps of Jodhpur district for the year 2015, 2016 and 2017 are presented in Fig.5-6. It was found that during the hot summer month of May, the area under NDVI class $0-0.1$ is reduced from $98 \%$ during 2015 to $95 \%$ during 2017 with a simultaneous increase in area under NDVI class 0.1-0.2 from 2 to $5 \%$ (Table 1). This indicates an increase in permanent vegetation in the form of trees as most of the annual herbs and shrubs mostly remains dry during hot summer months. During the month of october, area under NDVI class 0.2-0.3 increased from almost negligible during May to $34-39 \%$ during normal or surplus rainfall year but only to $3 \%$ during a deficit year.

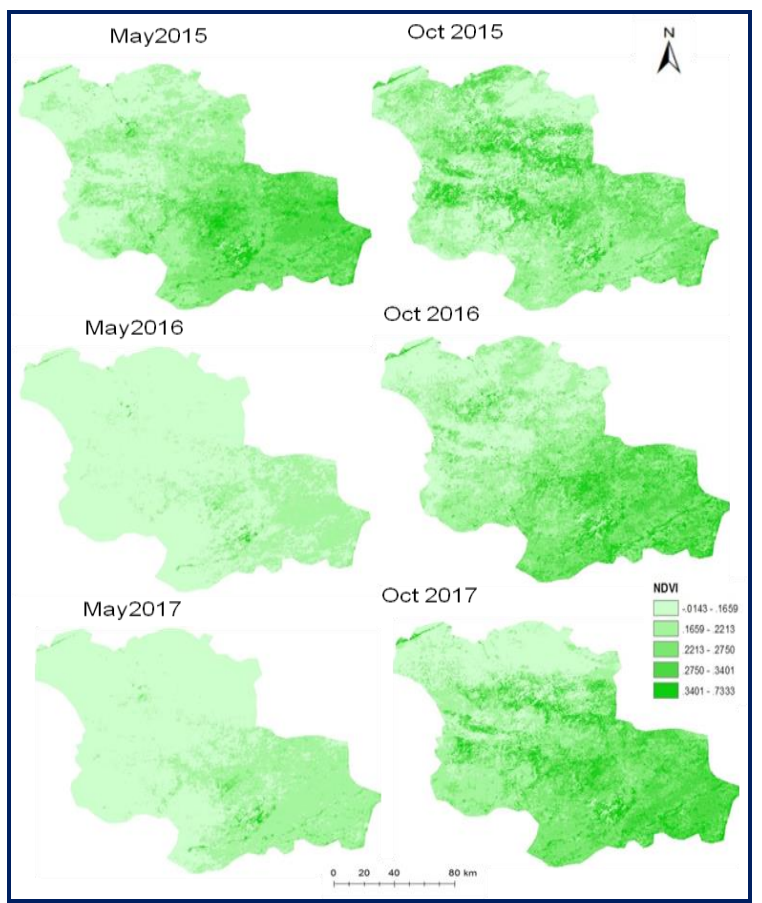

Fig.5: Temporal and spatial variation in NDVI of the study area.

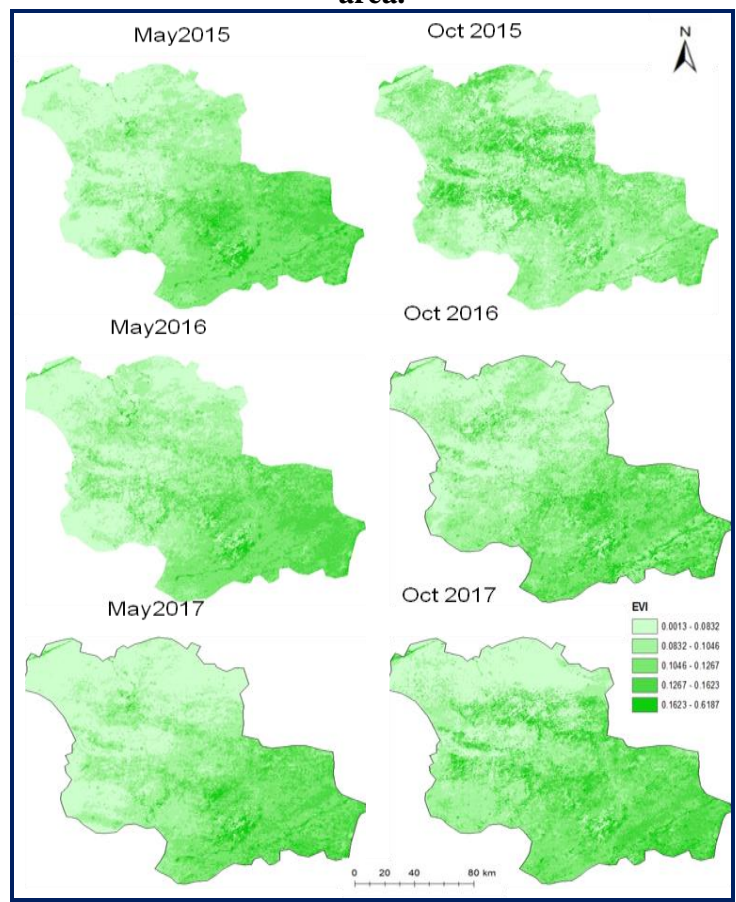

Fig.6: Temporal and spatial variation in EVI of the study area.

\subsection{Assessment of vegetation condition}

Distribution of NDVI values, extracted from MODIS terra remote sensing data indicates variation in greenness over the 
region from 2015 to 2017 . The time series analysis of NDVI values for the respective years is presented in Fig. 7. The MODIS images present an overview of the spatial changes in greenness in the region. Re-classification of above data into low, moderate and high (Fig. 7 and Table-1) using GIS indicates condition of vegetation and their spatial extent over the years. Area under high category was only experienced during Oct2017 (23.21\% area) and in May-2016 (22.10\% area) and Oct2015 with $10.27 \%$ area under high categories. In the moderate situation, during not so good rainfall years, the areas remained at par with $33-42 \%$ while in the low categories, the $\%$ area varied from 46 (Oct-2016) to 47 (Oct-2015) and in Oct-2017 $(35 \%)$ indicating situation of vegetation.

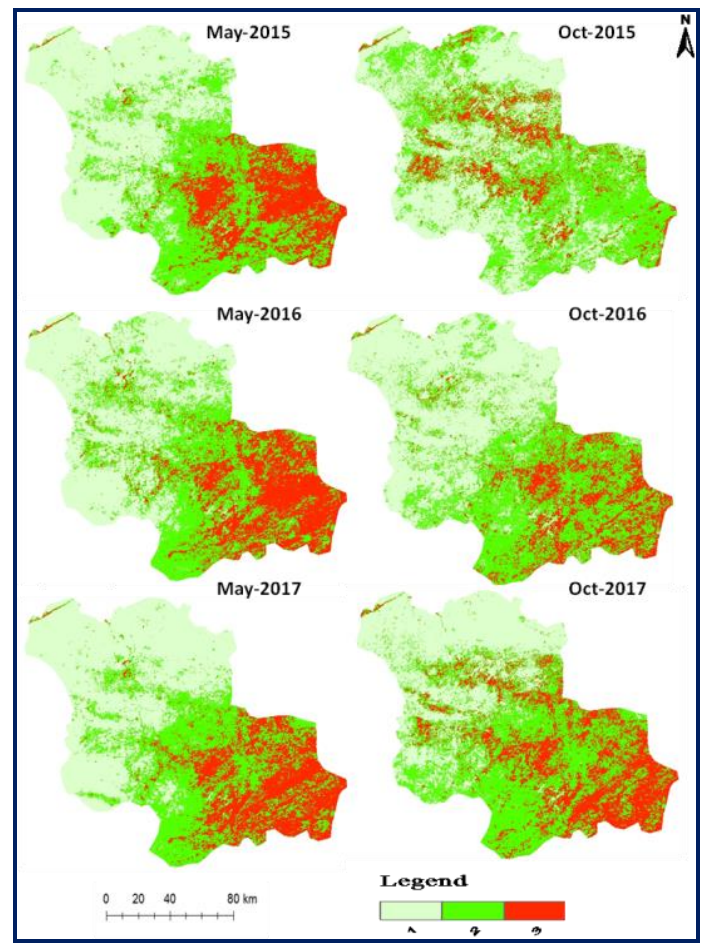

Fig.7. Reclassification of data showing sequential changes in NDVI over the years (2015-2017)

Table -1. Area statistics of different categories of NDVI values over the years in Jodhpur District

\begin{tabular}{|c|c|c|c|}
\hline $\begin{array}{l}\text { Categorie } \\
\text { s/ } \\
\text { Year }\end{array}$ & $\begin{array}{l}\text { Low } \\
(0- \\
0.24) \\
\text { Area } \\
\%\end{array}$ & $\begin{array}{l}\text { Moderate }(0 . \\
25-0.39) \\
\text { Area } \%\end{array}$ & $\begin{array}{l}\operatorname{High}(0.40 \\
-0.78) \\
\text { Area\% }\end{array}$ \\
\hline May 2015 & 45.50 & 35.00 & 19.50 \\
\hline Oct 2015 & 47.22 & 42.51 & 10.27 \\
\hline May 2016 & 43.79 & 34.11 & 22.10 \\
\hline Oct 2016 & 46.22 & 38.92 & 14.86 \\
\hline May 2017 & 45.46 & 33.36 & 21.18 \\
\hline Oct 2017 & 35.40 & 41.39 & 23.21 \\
\hline
\end{tabular}

Assessment and validation of natural vegetation coverage obtained from remote sensing is a important issue. Over the last three decades, remotely sensed data has offered a means of measuring vegetation properties at regional to global scales. MODIS-NDVI and EVI are closely tied to vegetation coverage, therefore NDVI and EVI will change closely natural vegetation coverage. Previous studies have used NDVI and EVI in semiarid climates. This study used MODIS NDVI and EVI, enabling comparison of the two indexes in a continental monsoon climate. In this study, EVI value would be expected to most closely correlate with natural vegetation coverage, because studies show that EVI was developed to improve sensitivity in high biomass regions, where NDVI tended to saturate, and the NDVI can result identifies the loss of dense forest cover canopies, regardless of forest type. NDVI can predict more reasonable data than EVI. So, among the two vegetation indices in this study, NDVI is more perfect for predicting natural vegetation coverage. The NDVI change detection generated from ArcGIS software is given in Fig.8. The Area statistics of different categories of NDVI values over the years in Jodhpur district is shown in Fig.9.

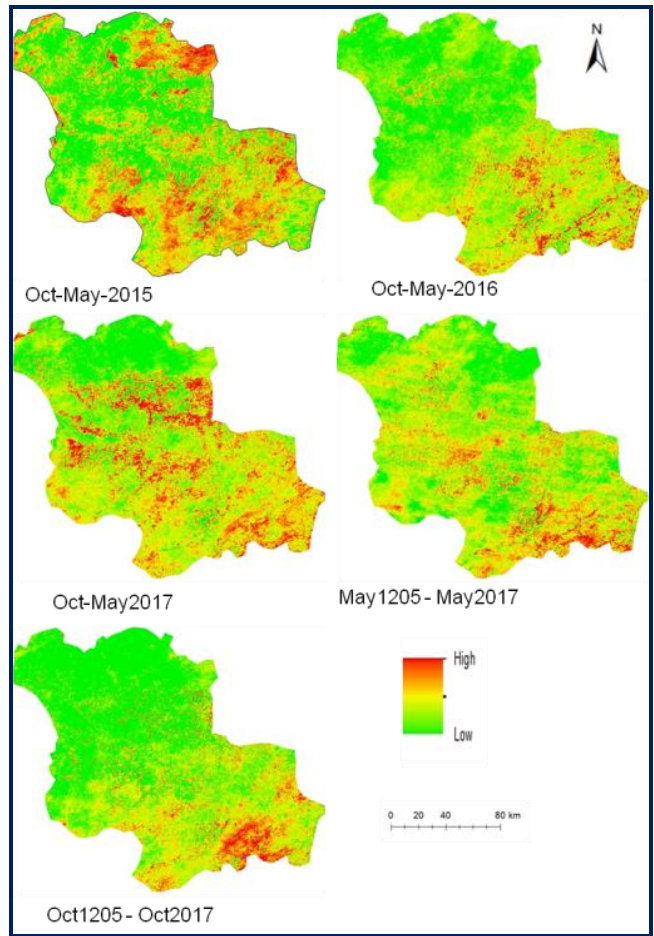

Fig.8. NDVI Change Detection of the Study Area.

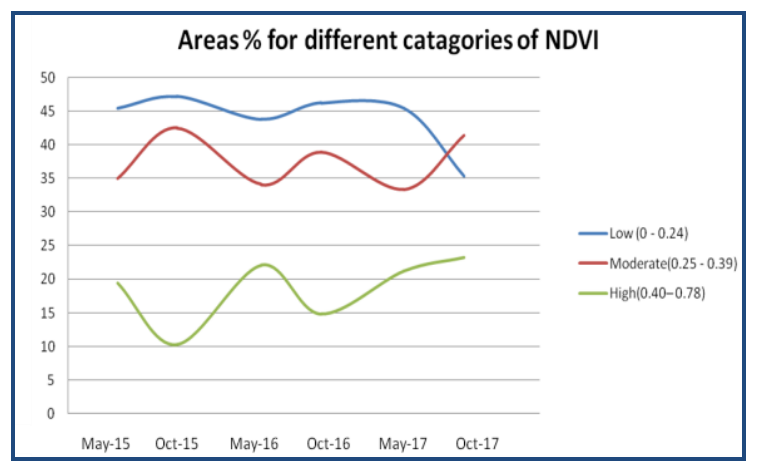

Fig.5. NDVI Categories over the years in Jodhpur District

\subsection{CONCLUSION}

The objective of this research was to evaluate the applicability of time-series MODIS $250 \mathrm{~m}$ data for large-area vegetation mapping in the arid district of Jodhpur.From this study, it has been found that MODIS NDVI products may be used to quickly 
assess the vegetation changes in response to rainfall as well as due to anthroprogenic interventions in arid region. The sensitivity of the MODIS to these regional variations also illustrates the considerable potential of these data for crop condition monitoring and phenology studies. It was also found that MODIS' $250 \mathrm{~m}$ spatial resolution was an appropriate scale at which to map the general vegetation patterns of the area. The MODIS data should also be tested for mapping specific crop rotation sequences.

\section{ACKNOWLEDGMENTS}

The authors are thankful to the Director DL, Jodhpur for his help during the study. The authors are also thankful to Head Remote Sensing Group for his critical suggestions and encouragement.

\section{REFERENCE}

Borana S. L. and S.K.Yadav, NDVI-based vegetation changes and Seasonal variation In Semi Arid region, ESRI Inndia Conference-2018, September 10-11, 2018Volume: 19.

Borana S. L., S.K.Yadav an S.K.Parihar, Spatio-Temporal Assessment of Vegetation Cover of Jodhpur City and Surrounding Areas, International Journal of Innovative Research in Computerand Communication Engineering, Vol. 5, Issue 10, October 2017

Dutta, Dipanwita, Arnab Kundu, N.R. Patel, S.K. Saha and A.R. Siddiqui, Assessment of agricultural drought in Rajasthan (India) using remote sensing derived Vegetation Condition Index (VCI) and Standardized Precipitation Index (SPI), The Egyptian Journal of Remote Sensing and Space Sciences (2015) 18 , pp. 53-63.

K. Didan. 2015. MOD13Q1 MODIS/Terra Vegetation Indices 16-Day L3 Global 250m SIN Grid V006. NASA EOSDIS Land Processes

https://doi.org/10.5067/MODIS/MOD13Q1.006

Moharana, P.C., Shalu Soni and R.K.Bhatt, Ndvi Based Assessment of Desertification In Jaisalmer District of Rajasthan in Reference to Regional Climate Variability.

ORNL DAAC. 2018. MODIS and VIIRS Land Products Global Subsetting and Visualization Tool. ORNL DAAC, Oak Ridge, Tennessee, USA. Accessed December 28, 2018. Subset obtained for MOD13Q1 product at 26.1948N,73.0371E, time period: 2015-01-01 to 2018-11-17, and subset size: $100.25 \mathrm{x}$ $100.25 \mathrm{~km}$. https://doi.org/10.3334/ORNLDAAC/1379.
Ramakrishna and C.V. Naidu, The Thar, Rajputana desert unprecedented rainfall in 2006 and 2010: effect of climate change?, Geofísica Internacional (2011) 50-4: pp. 363-370.

Saharan, M. A.; Vyas, N.; Borana, S. L.; Yadav, S. K., Classification and Assessment of the Land Use - Land Cover Changes in Jodhpur City Using Remote Sensing Technologies, International Archives of the Photogrammetry, Remote Sensing \& Spatial Information Sciences. 11/20/2018, Vol. XLII-5, p767771. 5p.

Santra, P. and Chakraborty, A. 2011. Analysis of seasonal and annual change of vegetation in the Indian Thar Desert using MODIS data, v. XXXVIII-8/W20, ISPRS Bhopal workshop, 8 November 2011.pp. 175-178.

sequestration and climate change mitigation. Advances in Forestry Science. Adv. For. Sci., Cuiabá, v.2, n.2, pp .23-33, 2015

Singh, Kaushal, Genda Singh, Roadside vegetation diversity of Jodhpur district and its role in carbon

Sur, Koyel, Rucha Dave and Prakash Chauhan, Spatio temporal changes in NDVI and rainfall over Western Rajasthan and Gujarat region of India, Journal of Agrometeorology 20 (3) : pp. 189-195 (September 2018).

Thenkabail, P.S., Gamage, M.S.D.N., Smakhtin, V.U., 2004. The use of remote sensing data for drought assessment and monitoring in Southwest Asia. Research report. 85, Int. Water. Manage. Inst. Colombo, Sri Lanka.

Vadlamudi Brahmananda Rao, Egidio Arai, Sergio $\mathrm{H}$. Franchito, Yosio E. Shimabukuro, S.S.V.S.

Vaidehi Chhajer, Sumati Prabhakar and P. Rama Chandra Prasad, Development of index to assess drought conditions using geospatial data a case study of Jaisalmer district, Rajasthan, India, journal Geoinformatica Polonica, 14: 2015, DOI 10.1515/gein-2015-0003.

Wardlow, Brian D.; Egbert, Stephen L.; and Kastens, Jude H., "Analysis of Time-Series MODIS $250 \mathrm{~m}$ Vegetation Index Data for Crop Classification in the U.S. Central Great Plains" (2007). Drought Mitigation Center Faculty Publications. 2. pp. 290310.

Yadav, S.K. and Borana, S.L, Monitoring and Temporal Study of Mining Area of Jodhpur City Using Remote Sensing and GIS, Int. Research Journal of Eng and Technology, Vol: 04 Issue:10,2017.2. 